J-DEPACE, Volume 3, Nomor 1, Juni 2020, Hal 209-219

Tersedia online di :http://jurnal.lpmiunvic.ac.id/index.php/jpkm

\title{
BIMBINGAN TEKNIS PENINGKATAN PRODUKTIVITAS UKM DI KABUPATEN SORONG
}

\author{
Pitter Leiwakabessy ${ }^{1}$, Pujianti Irawan², Indri Wijayanti ${ }^{3}$, Muhamaad Yusro ${ }^{4}$, Hadadiah $^{5}$ \\ Program Studi Akuntansi Politeknik Saint Paul \\ 1pitter_leiwakabessy@yahoo.com*,
}

\begin{abstract}
ABSTRAK
UKM merupakan soko guru perekonomian di Indonesia. Akan tetapi, terdapat banyak hambatan dalam perkembangan usahanya yaitu keterbatasan dana yang dimiliki serta sulitnya mendapatkan sumber dana yang dapat dimanfaatkan untuk menjadi modal dalam mendukung produksi usaha mikro, keterbatasan SDM, tidak memiliki legalitas usaha, produktivitas usaha yang kecil, dan lain sebagainya. Guna meningkatkan produktifitas, kinerja pemasaran, akses pembiayaan, pengembangan SDM, dan kinerja kelembagaan sehingga perlu diadakannya pelaksanaan bimbingan teknis (BIMTEK). BIMTEK yang dilakukan dengan tema meningkatkan prroduktifitas UKM di Kabupaten Sorong. Kegiatan BIMTEK ini diikuti oleh 20 orang pelaku UKM pada setiap kegiatannya. Kegiatan BIMTEK ini diprioritaskan untuk meningkatkan kegiatan usaha di bidang keuangan, bidang pemasaran, bidang SDM, dan bidang produksi.
\end{abstract}

\section{Kata Kunci: Bimbingan Teknis, Peningkatan Produktivitas, UKM}

\begin{abstract}
UKM is the mainstay of economy teachers in Indonesia. However, there are many obstacles in the development of his business, namely limited funds owned and difficulty in obtaining sources of funds that can be used as capital in supporting micro-business production, limited human resources, lack of business legality, small business productivity, and so on. In order to increase productivity, marketing performance, access to finance, human resource development, and institutional performance, it is necessary to carry out the implementation of technical guidance (BIMTEK). BIMTEK which is carried out with the theme of increasing the productivity of SMEs in Sorong Regency. This BIMTEK activity was attended by 20 UKM players in each of its activities. BIMTEK activities are prioritized to increase business activities in the financial sector, marketing sector, human resources sector, and production sector.
\end{abstract}

Keywords: Technical Guidance, Productivity Improvement, UKM 


\section{PENDAHULUAN}

Usaha kecil merupakan salah satu ujung tombak perekonomian negara Indonesia, sektor ekonomi kreatif berkembang pesat dalam beberapa industri UMKM. Peran UMKM dalam menjadi motor penggerak perekonomian nasional sangatlah signifikan dalam satu dekade terakhir. Munculnya banyak pengusaha-pengusaha muda membuat sektor UMKM menjadi komoditi yang menjanjikan (Zusrony, E,dkk, 2019). Sejak saat ini peranan UMKM dalam menopang perekonomian nasional maupun regional dari tahun ke tahun baik eksistensi, ketangguhan maupun kontribusinya terus meningkat. Keberhasilan UMKM ini dikarenakan, pertama, UMKM tidak memiliki utang luar negeri dan tidak banyak utang ke perbankan. Kedua, sektor-sektor kegiatan UMKM, seperti pertanian, perdagangan, industri rumah tangga, dan lain-lainnya tidak bergantung sumber bahan baku dari luar negeri. UMKM menggunakan bahan baku lokal. Ketiga, walaupun belum semuanya, UMKM berorientasi ekspor. Dapat dikatakan UMKM merupakan soko guru perekonomian nasional Usaha mikro, kecil dan menengah (UMKM) memiliki peranan penting dalam perekonomian di Indonesia. UMKM memiliki proporsi sebesar 99,99\%. dari total keseluruhan pelaku usaha di Indonesia atau sebanyak 52,76 juta unit Data Badan Pusat Statistik (BPS) tahun 2009 tersebut juga menunjukkan bahwa UMKM terbukti berkontribusi sebesar 56,92\% dari total Produk Domestik Bruto (PDB) Indonesia.

Selain itu, UMKM memiliki kemampuan menyerap tenaga kerja (menyerap 97,3\% dari total angkatan kerja yang bekerja) dan memiliki jumlah yang besar dari total unit usaha di Indonesia serta kontribusi yang cukup besar terhadap investasi di Indonesia. Mengingat besarnya peran UMKM tersebut, maka pemerintah melalui instansi terkait terutama Kementerian Koperasi dan UKM telah meluncurkan berbagai program bantuan. Kebijakan pemerintah untuk mendorong usaha kecil dan menengah cukup serius. Undang-Undang No 20 Tahun 2008 tentang Usaha Mikro, Kecil dan Menengah menegaskan bahwa, usaha ini perlu diselenggarakan secara menyeluruh, optimal, dan berkesinambungan melalui pengembangan iklim yang kondusif, pemberian kesempatan berusaha, dukungan, perlindungan, dan pengembangan usaha seluas-luasnya.

Salah satu program dari Dinas Koperasi dan UMKM adalah dengan dibentuknya 
PLUT KUMKM Mandiri sebagai wadah yang dapat berfungsi untuk menyediakan jasa nonfinansial yang menyeluruh dan terintegrasi bagi KUMKM guna meningkatkan produktifitas, kinerja pemasaran, akses pembiayaan, pengembangan SDM, dan kinerja kelembagaan. Karena baru dibentuk sehingga penting sekali pengenalan akan suatu instansi yang mampu menampung aspirasi pengusaha mikro,kecil dan menengah maupun koperasi adalah dengan melakukan Bimbingan Teknis (BIMTEK). BIMTEK yang dilakukan dengan tema meningkatkan produktifitas KUMKM di Kabupaten Sorong guna memperkenalkan Pusat Layanan Usaha Terpadu (PLUT) KUMKM Kabupaten Sorong serta berbagai program yang akan dilakukan guna meningkatkan perkembangan UMKM.

\section{MASALAH}

Beberapa hambatan dalam perkembangan usaha kecil dan mikro adalah keterbatasan dana yang dimiliki serta sulitnya mendapatkan sumber dana yang dapat dimanfaatkan untuk menjadi modal dalam mendukung produksi usaha mikro, keterbatasan SDM, tidak memiliki legalitas usaha, produktivitas usaha yang kecil, dan lain sebagainya. Mengingat hal tersebut, salah satu upaya yang dilakukan Dinas KUMKM Kabupaten Sorong yaitu dengan dibentuknya PLUT- KUMKM Kabupaten Sorong yang akan menampung seluruh permasalahan UMKM Kabupaten Sorong serta mencari solusi maupun melakukan berbagai kegiatan yang dapat meningkatkan usaha.

\section{METODE}

Pelaksanaan kegiatan ini menggunakan metode Demplat Partisipatif, yaitu melakukan kegiatan dalam bentuk pemberian pendampingan tentang bagaimana upaya mendapatkan pendanaan atau bantuan permodalan guna mempertahankan keberlanjutan bisnis.

\section{HASIL DAN PEMBAHASAN}

Adapun hasil dan pembahasan dari kegiatan pengabdian kepada masyarakat sebagai dalam meningkatkan produktivitas UMKM di Kabupaten Sorong dapat diuraikan sebagai berikut: 


\section{a. Bagian Pembiayaan dan Kelembagaan}

\begin{tabular}{|l|c|l|}
\hline Nama Kegiatan & $:$ & $\begin{array}{l}\text { BIMTEK : "Peningkatan Produktivitas KUMKN Di } \\
\text { Kabupaten Sorong" }\end{array}$ \\
\hline $\begin{array}{l}\text { Waktu } \\
\text { Pelaksanaan }\end{array}$ & $:$ & September 2018 \\
\hline Tempat & $:$ & Distrik Mariat Kabupaten Sorong \\
\hline Peserta & $:$ & 20 UMKM Di Kabupaten Sorong \\
\hline
\end{tabular}

Kegiatan yang dilaksanakan pada tanggal 29 September yang bertempat di salah satu pemilik UMKM, jalan Kenanga Mariat, Kabupaten Sorong yang dihadiri oleh 20 pelaku UMKM bertujuan untuk memberikan informasi seputar pengenalan Pusat layanan Usaha Tepadu (PLUT) yang merupakan lembaga yang menyediakan jasa non-finansial yang menyeluruh dan terintegrasi bagi KUMKM guna meningkatkan produktifitas, kinerja pemasaran, akses pembiayaan, pengembangan SDM, dan kinerja kelembagaan. Dengan adanya kegiatan ini para pelaku UMKM dapat mengetahui peranan PLUT serta pendampingan yang dibutuhkan. Sebagai contoh ; apabila ada UMKM yang terkendala pembiayaan atau alat produksi sehingga menurunkan tingkat produktifitas usaha, maka konsultan akan melakukan pendampingan dan membantu menyelesaikan masalah. Demikian juga pelaku UMKM yang mengalami kendala kelembagaan, SDM maupun pemasaran dapat langsung menghubungi para konsultan dan diharapkan produktifitas UMKM dapat meningkatkan setelah dilakukan pendampingan. Selain itu juga, bagi usaha yang berbentuk mikro, Kecil dan menengah, legalitas usaha sangat bermanfaat bagi kemajuan usaha. Agar kedepannya , usaha dapat berjalan dengan baik maka usaha harus memiliki izin secara legal. Bukan hanya usaha yang skala besar saja tetapi usaha skala kecil juga perlu memiliki legalitas usaha. Tetapi kenyataanya banyak pelaku UMKM belum memiliki izin Usaha Mikro Kecil ( IUMK). Dengan adanya legalitas usaha, maka akan mempermudah pengusaha untuk mengembangkan usaha.. Ada beberapa keuntungan yang diperoleh jika memiliki IUMK yaitu :

a. Mendapat kepastian perlindungan hokum dalam usaha sesuai dengan lokasi yang sudah ditetapkan. 
b. Mendapatkan kemudahan dalam pemberdayaan baik dari pusat, provinsi maupun daerah.

c. Mendapatkan kemudahan dalam mengakses pembiayaan ke berbagai lembaga keuangan bank maupun non bank

d. Mendapatkan pendampingan untuk pengembangan usaha yang lebih besar

e. Mendapatkan pengakuan yang sah dari berbagai pihak atas izin yang dimiliki dan dapat dipertanggungjawabkan secara hokum

f. Mendorong para pelaku bisnis UKM untuk sadar pajak sehingga dapat bermanfaat untuk kemajuan usahanya.

g. Menjadi nilai plus dari pada bisnis UKM lain yang tidak memiliki IUMK

Dari kegiatan BIMTEK ini juga, pelaku UMKM dapat memiliki pemahaman akan pentingnya kepemilikan izin usaha yaitu IUMK.
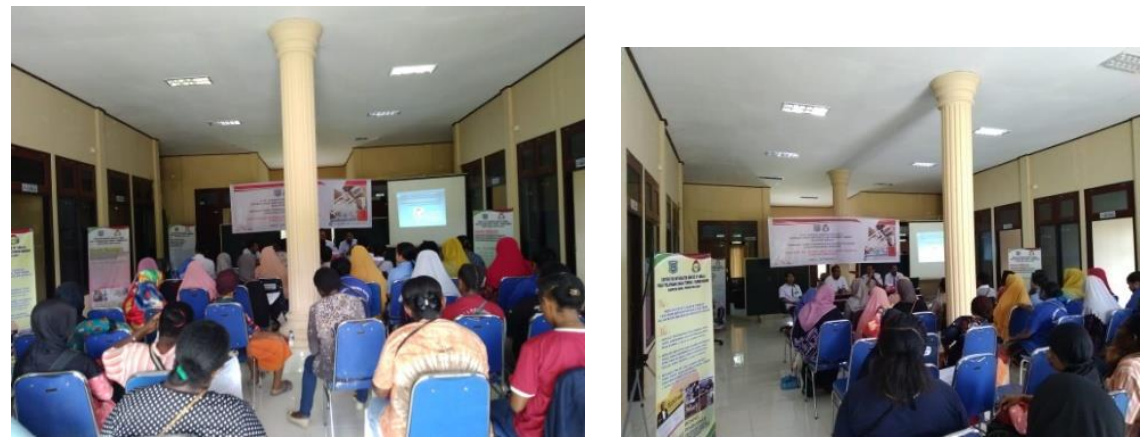

Gambar 1. BIMTEK : Peningkatan Produktivitas KUMKN Di Kabupaten Sorong Bidang Pembiayaan

b. Bidang Sumber Daya Manusia (SDM)

\begin{tabular}{|l|c|l|}
\hline Nama Kegiatan & $:$ & $\begin{array}{l}\text { BIMTEK dalam rangka sosialisasi sekaligus pengenalan } \\
\text { wadah PLUT kepada ibu-ibu Papua Pengrajin Noken dan } \\
\text { Penjual Pinang }\end{array}$ \\
\hline $\begin{array}{l}\text { Waktu } \\
\text { Pelaksanaan }\end{array}$ & $:$ & September 2018 \\
\hline Tempat & $:$ & Alun-Alun Aimas Kabupaten Sorong Jl. Sorong Klamono \\
\hline
\end{tabular}




\begin{tabular}{|l|l|l|}
\hline & & Km 18. \\
\hline Peserta & $:$ & Pengrajin Noken dan Penjual Pinang yang Produktif \\
\hline
\end{tabular}

Kegiatan BIMTEK di bidang SDM adalah untuk memperkenalkan wadah PLUT dibawah kementrian Koperassi yang belum lama dibentuk di Kabupaten Sorong. kegiatan yang dilakukan terkait dengan bidang SDM adalah :

1. Memberikan konsultasi untuk mencari solusi atas permasalahan yang dihaddapi para pelaku UKM

2. Memberikan informasi kepada para pelaku UKM bahwa keberadaan PLUT KUMKM Mandiri sebagai wadah yang dibentuk untuk membantu mengarahkan dan mengembangkan keberlanjutan bisnis UMKM dari segi pembiayaan, kelembagaan, SDM, maupun produksi.

3. Melakukan pendampingan untuk menemukan masalah dan solusi terutama masalah legalitas usaha.

4. Memonitoring setiap kegiatan pelaku UKM dalam menjalankan usaha agar tetap survive

5. Melakukan kegiatan pelatihan

Dari hasil pertemuan tersebut ditemukan permasalahn umum yang dihadapi yaitu masalah pemasaran produk noken. Karena sistem pemasaran yang diterapkan masih face to face sehingga belum banyak yang mengetahui keberaan produk yang dijual oleh pelaku UMKM tersebut, sedangkan bagi penjual pinang yaitu terkendalanya alat pemotong pinang.

\begin{tabular}{|l|c|l|}
\hline Nama Kegiatan & $:$ & $\begin{array}{l}\text { BIMTEK Bidang SDM Pendampingan dan Pengelolaan } \\
\text { PLUT - KUMKM Kabupaten Sorong Terhadap pelaku } \\
\text { UMKM bahan tradisional yaitu sarang semut, UMKM } \\
\text { Pancing Bengkel dan Bakso }\end{array}$ \\
\hline $\begin{array}{l}\text { Waktu } \\
\text { Pelaksanaan }\end{array}$ & $:$ & September 2018 \\
\hline Tempat & $:$ & Rumah Spot Pancing Bapak Syukur di SP 2 Aimas \\
\hline
\end{tabular}




\begin{tabular}{|l|l|l|}
\hline & & Kabupaten Sorong \\
\hline Peserta & $:$ & $\begin{array}{l}\text { Pelaku UMKM Di Daerah satuan pemukiman 2 Aimas } \\
\text { Kabupaten Sorong }\end{array}$ \\
\hline
\end{tabular}

Pada kesempatan ini tim dan Kepala Dinas Koperasi dan UMKM Kabupaten Sorong berkesempatan hadir memberikan penjelasan tentang apa itu PLUT, Tujuan Plut, sasaran dan program PLUT itu sendiri. Kondisi yang terjadi terkait dengan pengembangan UMKM di daerah ini terbilang cukup maju. UMKM pun terlihat berkembang secara baik. Hal ini juga yang membuat pemerintah mendirikan Pasar Induk di daerah Mariyai yang kedepan akan dijadikan pasar besar yang menyediakan aneka ragam hasil bumi. Permasalahannya tidak terlalu banyak hanya perlu sedikit tambahan pengetahuan melalui kegiatan pelatihan dan persyaratan guna melengkapi legalitas usaha.
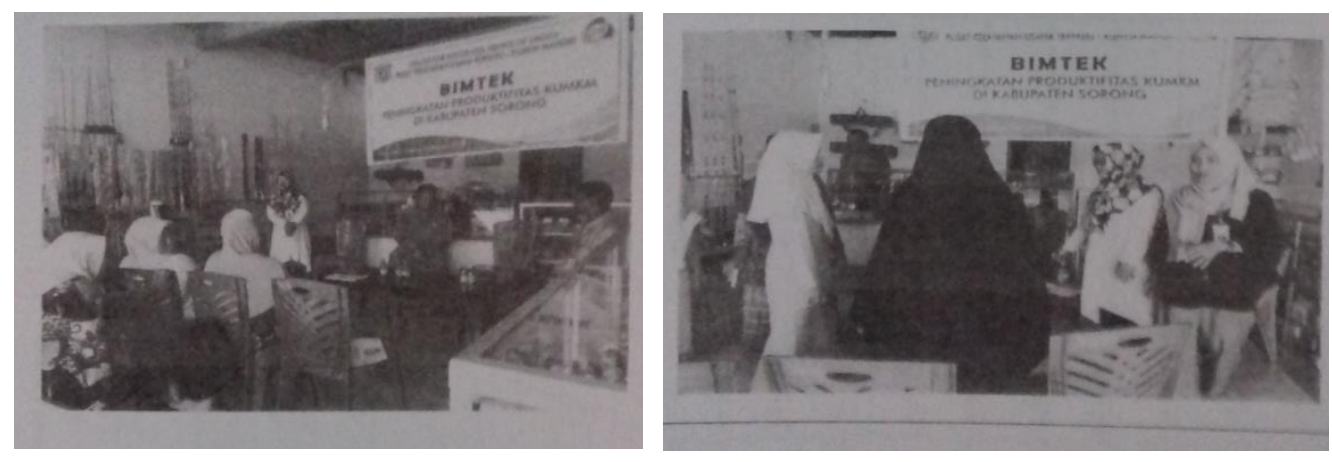

Gambar 2. BIMTEK : Peningkatan Produktivitas KUMKN Di Kabupaten Sorong Bidang SDM

\section{c. Bidang Produksi}

\begin{tabular}{|l|c|l|}
\hline Nama Kegiatan & $:$ & Peningkatan Produktivitas KUMKM di Kabupaten Sorong \\
\hline Waktu & $:$ & September 2018 \\
Pelaksanaan & & \\
\hline Tempat & $:$ & Jalan Durian Kelurahan Malawili Kecamatan Aimas \\
\hline Peserta & $:$ & $\mathbf{2 0}$ orang pelaku UMKM \\
\hline
\end{tabular}


PLUT KUMKM merupakan lembaga yang memberikan pendampingan dan pemberdayaan lainnya kepada koperasi dan UKM secara konprehensif dan terpadu untuk meningkatkan produksi, produktivitas, nilai tambah dan daya saing UMKM, maka lembaga ini hadir untuk memberikan layanan pendampingan bagi para pelaku UMKM agar mampu meningkatkan produktivitas dan daya saingnya. Selain itu, dengan berkembangnya teknologi, kemasan bukan hanya berfungsi sebagai pelindung produk untuk dipasarkan, namun seiring berjalannya waktu, kini kemasan berfungsi sebagai media promosi dan juga merupakan identitas diri dari produk yang ada. Bagi para pelaku UMKM untuk bersaing dengan produk perusahaan besar. Beberapa masalah seperti keterbatassan SDM, keterbatasan modal, akses passer dan volume produksi membuat sebagian pelaku UMKM tidak menganggap kemasan menjadi unsure penting untuk usaha mereka. Maka kegiatan ini dihadirkan untuk memberikan wawasan pada pelaku UMKM tentang pentingnya label pada produk UMKM dan bagaimana kaidah yang benar dalam membuat sebuah label kemasan. Dari kegiatan ini beberapa pelaku UMKM mengaku terkendala masalah legalitas produk mereka sehingga tidak berani membuat label untuk produk-produk mereka.

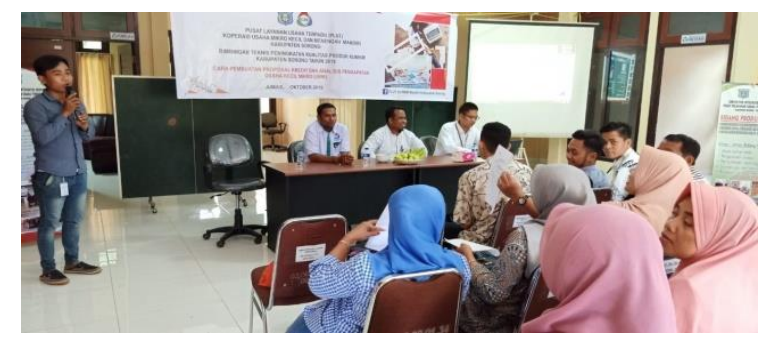

Gambar 3. BIMTEK : Peningkatan Produktivitas KUMKN Di Kabupaten Sorong Bidang Produksi

\section{d. Bidang Pemasaran}

\begin{tabular}{|l|c|l|l|}
\hline Nama Kegiatan & $:$ & $\begin{array}{l}\text { BIMTEK : Peningkatan Produktivitas KUMKM di } \\
\text { Kabupaten Sorong }\end{array}$ & \\
\hline Waktu & $:$ & September 2018 & \\
\hline
\end{tabular}




\begin{tabular}{|l|c|l|}
\hline Pelaksanaan & & \\
\hline Tempat & $:$ & Jalan Poros Makbusun Kabupaten Sorong \\
\hline Peserta & $:$ & 20 orang pelaku UMKM \\
\hline
\end{tabular}

Kegiatan BIMTEK yang dilaksanakan ini merupakan kegiatan yang diselenggarakan oleh konsultan pendamping PLUT KUMKM Mandiri Kabupaten Sorong. Dalam kegiatan ini,, menjelaskan fungsi PLUT KUMKM- Kabupaten Sorong serta memberikan materi khususnya bidang pemasaran yang menjelaskan tentang strategi pemasaran yang efektif untuk para pelaku UMKM. Adapun kelima strategi yang efektif yaitu :

1. Membuat produk yang unik

Buatlah produk yang unik dan memiliki kelebihan dibandingkan dengan produk lain yang sejenis.pesaing tentu ada di mana-mana, jika produk atau jasa yang ditawarkan tidak emiliki kelebihan, maka akan sulit untuk bersaing. Bukan hanya itu, selain unik dan berkualitas, produk yang ingin dijual harus dapat memenuhi kebutuhan konsumen. Seiring dengan perkembangan zaman dan teknologi, kebutuhan konsumen pun ikut berubah. Oleh karena itu, inovasi harus selalu dilakukan secara berkala. Hal ini untuk membantu dalam persaingan pasar dan membuat pelanggan tetap loyal terhadap produk yang dijual.

2. Menjadi networker

Networker adalah seseorang yang memiliki jaringan yang sangat luas dan memiliki sifat optimis dalam menjalankan bisnis. Jika anda bukanlah seorang networker yang kompeten, maka sekarang adalah waktu yang tepat bagi anda untuk belajar menjadi seorang networker. Jika kurang percaya diri, anada dapat memperkerjakan seorang tenaga pemasaran yang dapat diandalkan sebagai unjung tombak untuk perluasan jaringan UKM anda.

\section{Menentukan STP}

STP merupakan singkatan dari segmenting, targeting, anfdpositioning. Dimana tiga hal tersebut sangat berhubungan satu sama dengan yang lain. Untuk memasarkan produk UKM, maka perlu ditentukan segmentasi pasar yaitu menempatkan konsumeb dalam sub kelompok produk, sehingga pembeli memiliki tanggapan yang hamper sama 
dengan strategi pemasaran dalam menentukan posisi perusahaan. Dalam menentukan targeting kita harus mengevaluasi berbagai segmen tersebut untuk memutuskan siapa yang akan menjadi target market kita. Tahap yang berikutnya adalah posisi produk yang merupakan kombinasi kegiatan pemasaran yang dilakukan manajemen untuk memenuhi kebutuhan dan keinginan setiap pasar sasaran. Ketiga hal tersebut harus dilakukan secara baik untuk mencapai pemasaran yang sukses,.

4. Memanfaatkan E-Commerce

Dengan memanfaatkan $e$-commerce, bisnis memiliki peluang untuk menjangkau pasar yang lebih luas dan global. E-commerce dalam dunia bisnis dapat mendukung pemotongan rantai distribusi sehingga konsumen dapat memperoleh suatu produk dengan harga yang lebih murah. Pemasaran dengan e-commerce memiliki beberapa manfaat antara lain murah dan efisien, memiliki akses tanpa batas, dan memperpendek jarak distribusi produk.

5. Konsisten

Konsisten dalam menjalankan strategi pemasaran merupakan hal penting. Selain kreatif, pelaku UKM juga dituntut untuk dapat terus konsisten dalam menjalankan strategi pemasaran yang dipilih. Hal ini penting karena kepercayaan konsumen akan terbangun apabila anda konsisten di bidang usaha yang digeluti dan menjadi seorang ahli didalamnya.

\section{KESIMPULAN DAN SARAN}

Usaha kecil merupakan salah satu ujung tombak perekonomian negara Indonesia, sektor ekonomi kreatif berkembang pesat dalam beberapa industri UMKM. Peran UMKM dalam menjadi motor penggerak perekonomian nasional sangatlah signifikan dalam satu dekade terakhir. Munculnya banyak pengusaha-pengusaha muda membuat sektor UMKM menjadi komoditi yang menjanjikan Akan tetapi, terdapat banyak hambatan dalam perkembangan usahanya yaitu keterbatasan dana yang dimiliki serta sulitnya mendapatkan sumber dana yang dapat dimanfaatkan untuk menjadi modal dalam mendukung produksi usaha mikro, keterbatasan SDM, tidak memiliki legalitas usaha, produktivitas usaha yang kecil, dan lain sebagainya. Guna meningkatkan produktifitas, kinerja pemasaran, akses 
pembiayaan, pengembangan SDM, dan kinerja kelembagaan sehingga perlu diadakannya pelaksanaan bimbingan teknis (BIMTEK). BIMTEK yang dilakukan dengan tema meningkatkan prroduktifitas UKM di Kabupaten Sorong. Kegiatan BIMTEK ini diikuti oleh 20 orang pelaku UKM pada setiap kegiatannya. Kegiatan BIMTEK ini diprioritaskan untuk meningkatkan kegiatan usaha di bidang keuangan, bidang pemasaran, bidang SDM, dan bidang produksi.

\section{DAFTAR PUSTAKA}

Anggraeni Feni Dwi Anggraeni, Imam Hardjanto, Dan Ainul Hayat. Pengembangan Usaha Mikro, Kecil, Dan Menengah (UMKM) Melalui Fasilitasi Pihak Eksternal Dan Potensi Internal (Studi Kasus Pada Kelompok Usaha “Emping Jagung” Di Kelurahan Pandanwangi Kecamatan Blimbing, Kota Malang) Jurnal Administrasi Publik (JAP), Vol. 1, No. 6, Hal. 1286-1295

Leiwakabessy, P., \& Lahallo, F. F. (2018). Pembiayaan Usaha Mikro Kecil dan Menengah (UMKM) sebagai Solusi dalam Meningkatkan Produktivitas Usaha pada UMKM Kabupaten Sorong. Journal of Dedication to Papua Community (J-DEPACE), 1(1), 11-21.

Zusrony, E., Zainudin, A., Purhita, E. J., Santoso, A. B., Widyaningsih, D., \& Dianta, I. A. (2019). Pelatihan Dan Penyuluhan Tata Kelola Organisasi Bagi UMKM CV. Bonanza Di Boyolali Untuk Meningkatan Kinerja Perusahaan. J-DEPACE (Journal of Dedication to Рариа Community), 2(2), 150-156. 